\title{
Limited results of group self-management education for rheumatoid arthritis patients and their partners: explanations from the patient perspective
}

\author{
Christina Bode • Erik Taal • Pascale A. A. Emons • \\ Mirjam Galetzka • Johannes J. Rasker • \\ Mart A. F. J. Van de Laar
}

Received: 11 December 2007 /Revised: 25 April 2008 / Accepted: 19 June 2008 / Published online: 18 July 2008

(C) The Author(s) 2008

\begin{abstract}
This study aimed to identify the reasons for limited results of group self-management for RA patients and their partners from the patient perspective. Semistructured interviews with ten male and ten female patients who had participated in group self-management with or without their partner were content analyzed with respect to motivation to participate and the effects of the program on them. The limited effects of the self-management program appear to be linked with low motivation to participate and to change health behavior. The data show that a decline in health and also stressful life events might be associated with the disappointing effects of the program. Three strategies were proposed for improving the program's effects: (a) provide information about the program in advance to ensure that patients have appropriate expectations. (b) Enhance intrinsic motivation to change health behavior by counseling techniques. (c) Tailoring with respect to motivation and current concerns could help to form more homogeneous groups or could be the basis for a tailored online intervention.
\end{abstract}

C. Bode $(\bowtie) \cdot$ E. Taal P. A. A. Emons $\cdot$ J. J. Rasker $\cdot$

M. A. F. J. Van de Laar

Department of Psychology and Communication of Health and Risk, University of Twente,

P.O. Box 217, 7500 AE Enschede, The Netherlands

e-mail: c.bode@utwente.nl

M. Galetzka

Department of Marketing Communication

and Consumer Psychology, University of Twente,

P.O. Box 217, 7500 AE Enschede, The Netherlands

J. J. Rasker • M. A. F. J. Van de Laar

Medisch Spectrum Twente,

Enschede, The Netherlands
Keywords Effectiveness - Motivation · Partner participation Patient education . Patient perspective $\cdot$ Rheumatoid arthritis

\section{Introduction}

This study examined possible reasons for the limited effects of a Dutch adaptation of the Arthritis Self-Management Program (ASMP), attended by rheumatoid arthritis (RA) patients either with or without their partners [1]. A qualitative follow-up approach has been chosen since the previous effect study failed to fully explain the results. Effects of the ASMP on self-efficacy, health behaviors, health status, and health care utilization have been documented in many studies [2-5]. However, at least two studies with primary care patients reported limited results $[6,7]$. In general, the effects of patient education programs for adults with RA are robust but short lived [8]. Riemsma et al. [1] investigated the effects of a Dutch adaptation of the ASMP for RA patients and compared patients who participated alone with patients who participated with a significant other, usually a partner (Partner Participation Project, PPP). After 12 months, self-efficacy scores were significantly higher for patients participating without a partner and significantly lower for patients participating with a partner. Fatigue increased in patients participating with a partner and decreased in patients participating without a partner. No effects were found on health status, health behavior, or social interactions.

Reasons for the limited effects of the ASMP as such and reasons related to partner participation were discussed $[1,9]$. Active partner participation in the program was expected to improve support adequacy, which in turn should improve patients' self-efficacy. The effect study [1], however, did 
not support these expectations. This result might be caused by a lack of specific attention to family relationships and the effect of arthritis on these relationships. Other studies on involving close relatives in programs for RA and OA patients reported mixed results [10-12].

Motivation of participants and partners may have played a role in the mixed results of the PPP. According to the transtheoretical model [13], intervention strategies and motivational stages of participants have to be matched to achieve optimal effects. A recent systematic review, however, showed limited evidence for the assumption that tailoring according to motivational stage substantially improves effects [14].

In adjusting to a chronic illness, patients pass through phases of denial, anxiety, and depression [15]. The emotional state of the patient may influence the effects of a self-management program. The current study aimed to examine whether, at the time of participation, patients were open to new information, advice, and exercises.

Satisfaction with allocation to groups (with/without partner) might also have influenced the effects, assuming that peer support and modeling play a role in effectiveness $[16,17]$. These processes could be influenced by the presence of a partner $[18,19]$. To avoid negative effects of family participation, Helgeson and Gottlieb [18] suggested separating peer group and natural network in cases where overprotection occurs. In the RCT of Riemsma et al. [1], the quality of the partner relationship was not applied as a criterion for inclusion. However, changes in support and overprotection were tested as explanation for the results. No effects were found.

The present investigation is a follow-up to the Riemsma study and analyzes motivational issues and reasons for the limited effects. Interviews were employed to reveal participants' own assessment of their motivation, whether the intervention was offered at an appropriate phase of their illness and whether they were satisfied with the "with partner'/'without partner' grouping. Moreover, patients were invited to describe perceived effectiveness and factors that have influenced effectiveness.

\section{Materials and methods}

\section{Participants}

Patients who showed a considerable increase or decrease in arthritis-related self-efficacy at 12 months compared to baseline scores [1] were included. Patients satisfying this criterion had to show a standardized effect size (=scores on self-efficacy at 12 months-baseline scores/standard deviation of the baseline scores) lower than -0.25 or higher than 0.25 on at least two of the three subscales of the Dutch version of the Arthritis Self-Efficacy Scale [20,9].
In the earlier RCT [1], the 218 RA patients who participated were selected from the outpatient clinics of two hospitals in the region of Twente (The Netherlands). The 76 patients in the RCT who were allocated to the control group and did not receive group education were excluded from this follow-up study.

Of the 51 patients meeting the inclusion criterion, 28 patients were selected for an equal balance of sex, age, and disease duration. Four groups resulted: with/without partner and improved/decreased self-efficacy. The selected patients were invited by their rheumatologists to participate.

Twenty of the 28 selected patients participated (ten men and ten women; mean age, 57 years; minimum 28 years; maximum 69 years). They had suffered from RA for an average of 11 years (minimum 1 year; maximum 25 years). Disease activity (DAS 28) was on average 4.4 (minimum 1.4; maximum 6.7), and patients reported on a visual analog scale (100 mm) $38.5 \mathrm{~mm}$ pain (minimum 7; maximum 85). Table 1 shows the distribution of the study population according to the analysis group.

\section{Data collection}

Semi-structured interviews were carried out by one interviewer (P.E.) who was not involved in the intervention and its effect evaluation. The study took place about 2 years after the program because the interview study was planned post hoc as follow-up to clarify the results of the RCT study.

Permission for the study was obtained from the Ethics Committee of the MST Hospital Enschede (The Netherlands).

\section{Data analysis}

Five questions led the analysis of the interview material (see Box 1). We used an approach that combines deductive and inductive elements of analysis. This approach is similar to the framework approach [21], but the deductive element is slightly more dominant. The interviews were taperecorded and transcribed verbatim. All transcripts were read and discussed by three researchers (P.E., E.T., and M.G.) to identify themes brought up by the participants. These themes resulted in a coding framework (codes shown in Tables 2 and 3). Another researcher (CB), who was not involved in the effect study and the interview study so far,

Table 1 Distribution patients PPP (participation number)

\begin{tabular}{lll}
\hline & Male & Female \\
\hline Without partner and decreased self-efficacy & 133,169 & $113,173,106$ \\
With partner and decreased self-efficacy & 51,68 & 32 \\
Without partner and increased self-efficacy & $144,155,166$ & $126,146,160$ \\
With partner and increased self-efficacy & $36,46,58$ & $5,42,43$ \\
\hline
\end{tabular}


repeated the identification of themes and discussed divergent categorizations with ET. The categories were grouped according to the individual result of the program (decline or improvement in arthritis related self-efficacy) and the experimental condition (presence/absence of partner). The citations presented in this article were translated by an English native speaker who is certified as official translator.

Box 1 Questions leading the analyses of the interview material

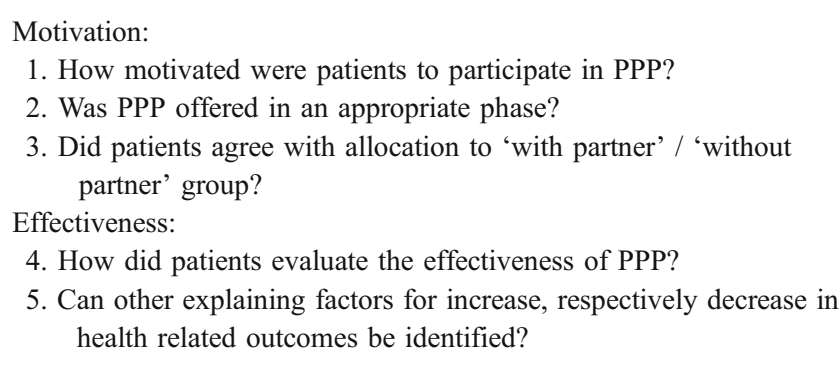

\section{Results}

Motivation for participation

Table 2 shows different aspects of motivation. Six patients (four in the group with increased SE and two in the decreased group) reported positive motives; they saw the program as an opportunity to improve their knowledge of RA and to exchange experiences with peers, and as an aid to managing RA.

P: The motive was (...) to learn how to deal with it. Of course you don't really know what to expect, and it can differ quite considerably. And that's also the weird thing about arthritis: Someone has this, the other has that. (58)

Three patients reported that they did not participate for themselves but wanted to support scientific progress.

\section{$P:$ (...) If it helps the doctors, then I want to cooperate,} even if it doesn't help me. (36)

Another four patients reported that they wished to please the rheumatologist. Three of these showed decreased selfefficacy after the program.

With regard to whether patients participated at an appropriate phase, three patients with increased selfefficacy were convinced that the program was offered to them at just the right time. Interestingly, these were patients with long disease durations ( $>11$ years). No patient with decreased self-efficacy reported that the program was offered at an appropriate phase.

Table 2 Motivation of participants in terms of the coding framework (participation number)

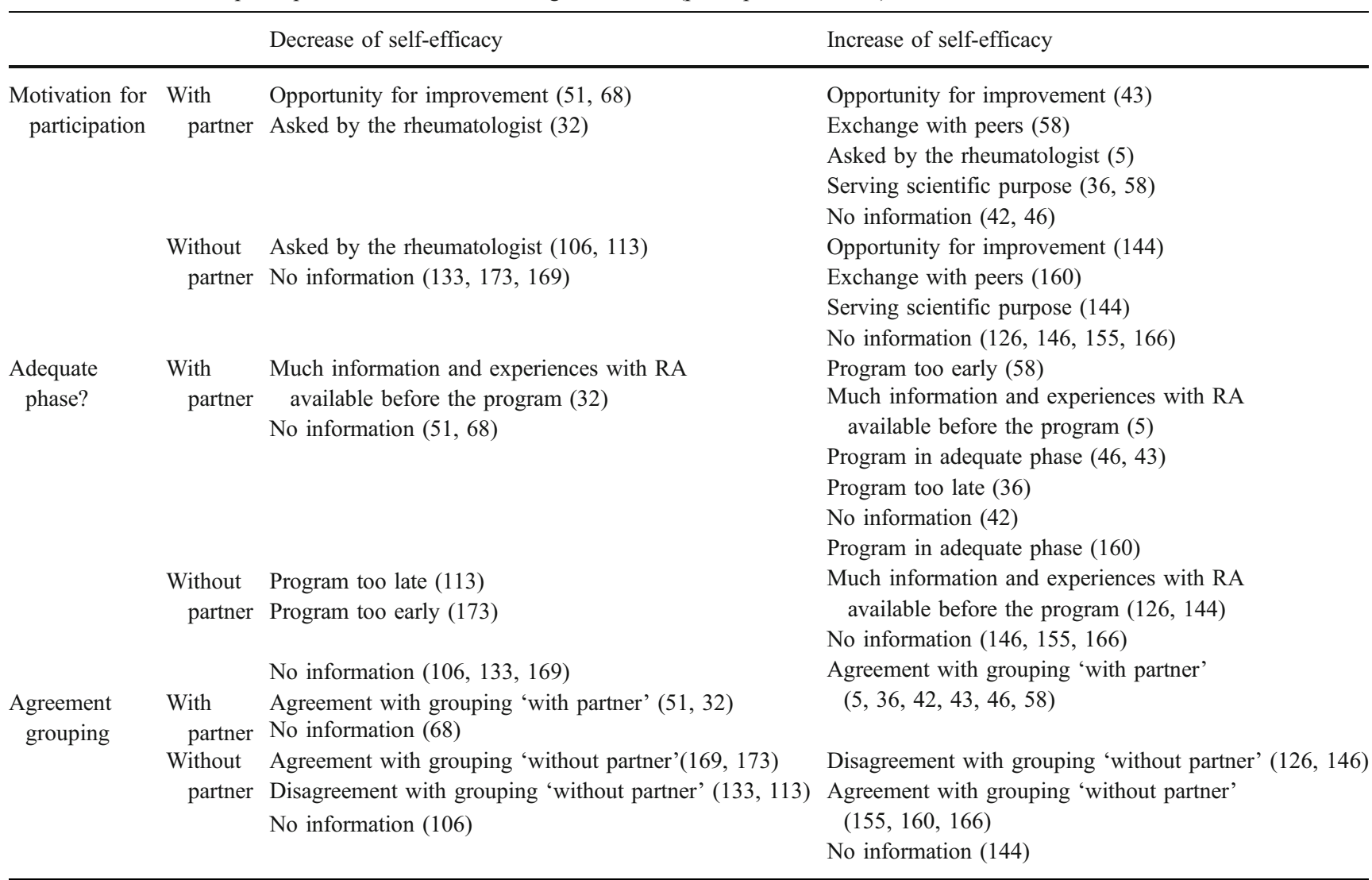


Patients from both outcome groups reported that the program was either too late or too early. Reasons given for 'too early' always referred to the absence of pain or other adverse consequences of RA.

Most patients in the 'with partner' condition were happy with the grouping (Table 2). For some patients, this was because they see arthritis as something to manage with their partner.

P: Because my wife accompanies me to the checkups at the hospital. Yes, because it's not as if you're the only one with arthritis. The illness also demands a lot from your family. They also have to adapt a lot. (58)

One participant said that she hoped for better contact and communication with her husband as a result of participation.

\section{I: What did you feel about his going with you?}

P: Yes, I was glad he did. Not only for me personally, but also because in a group like that you talk differently about it than you do at home. (...) (32)

In the 'without partner' condition, the pattern of agreement and disagreement was mixed. Patients who participated without a partner noted positive effects of this absence, e.g., easier communication with peers and the need to manage the program on one's own.

\section{P: With things like that I feel freer to talk when he's} not around. (173)

I: You were assigned to a group without partners. How was that for you?

P: No, it was okay, because I hid behind him, my husband always helps me with everything. He always gives me the strength to do it. Now I had to go there on my own. (...) So that was also something of a victory for me, so it was really good. (160)
Dissatisfaction with the condition 'without partner' came from the desire for better understanding and communication with the partner or from practical problems such as transport.

Effectiveness of the program from the patient perspective

Nearly all the patients who had increased self-efficacy (except patient 126) reported positive effects of the program, whereas in the decreased self-efficacy group, we saw both positive and negative evaluations (Table 3 ). Patients reported positive effects with regard to health behavior, e.g., reduction of work hours, controlled intensive exercise, and taking an afternoon nap. Other positive effects were related to psychological functioning, e.g., acceptance of arthritis, improvement of self-esteem, and new coping strategies.

P: I am glad that I did the course. It helped change the way I look at it a bit. I think attending the course resulted in me being a bit more aware. (...) It is not, (...) acceptance is a rotten word, because I won't ever accept it, not really, but I have accepted it now that it is there. And then you have to see how you deal with it. In a positive way. (68)

P: I started to withdraw more and more. I saw far too few people and through this I started to go out more. Because you had to commit yourself to cycling twice a week, the contract meant I had to do it, which meant going out more and meeting people again. They broke the circle for sure. (...)

(The illness...) is now more of a fact, something definite, and I can't ignore it any more, it is the way it is. (...) I used to say: "I'm not going to live with arthritis; the arthritis is going to have to learn to live

Table 3 Effectiveness from the patient perspective in terms of the coding framework (participation number)

\begin{tabular}{|c|c|c|c|}
\hline & & Decrease of self-efficacy & Increase of self-efficacy \\
\hline \multirow{8}{*}{$\begin{array}{l}\text { Individual evaluation } \\
\text { of effectiveness }\end{array}$} & \multirow[t]{3}{*}{ With partner } & Positive effect $(51,68)$ & Positive effect $(5,42,43,46,58)$ \\
\hline & & Recognition, peer support $(51,68)$ & Recognition, peer support $(36,42,43,46,58)$ \\
\hline & & No effect (32) & \\
\hline & \multirow[t]{5}{*}{ Without partner } & Positive effect (173) & Positive effect $(144,146,155,160,166)$ \\
\hline & & Recognition, peer support (169) & Recognition, peer support $(160,166)$ \\
\hline & & Maintenance of exercises (169) & Maintenance of exercises (146) \\
\hline & & Lack of recognition or peer support $(106,113)$ & No effect (126) \\
\hline & & No effect $(106,113,133)$ & \\
\hline \multirow[t]{6}{*}{ Other explanations for effects } & \multirow[t]{3}{*}{ With partner } & Negative events (51) & Decreased health $(5,46,58)$ \\
\hline & & Decreased health $(32,68)$ & No changes (43) \\
\hline & & & No information $(36,42)$ \\
\hline & \multirow[t]{3}{*}{ Without partner } & Negative events $(106,173)$ & Positive events (144) \\
\hline & & Decreased health $(113,133,173)$ & Decreased health (146) \\
\hline & & Overburdened (169) & No information $(126,155,160,166)$ \\
\hline
\end{tabular}


with me." But now I've changed a bit: now I live a less hectic life, I listen more to my body whereas I used to be rebellious. (160)

Recognition and peer support were also emphasized by patients from all research conditions.

\section{P: The knowledge that there were other women there of} my age, who were in the same boat, reassured me immensely, I wasn't alone any more. (...) And we still have strong ties with those women, so that has stayed. It's really the support of others in the same boat, because an outsider often doesn't know what it is like, and doesn't offer you as much. Then you've got to explain everything and even then they don't understand. (160)

Negative evaluations referring to lack of recognition and peer support were made by two patients in the 'without partner, decreased self-efficacy' group. These women expected to make lasting contacts or engage in intellectual conversation; both reported to be disappointed in this respect.

In all research conditions, we found patients who reported that they did not learn anything concrete, mainly because they already knew a lot about arthritis before the program. Patients who decreased in self-efficacy did not see any advantages, or they hoped that other patients had learned from them.

In contrast to these interpretations, at least two "wellinformed" patients in the increased self-efficacy group interpreted the situation as an endorsement of the ways they dealt with arthritis.

P: Yes, I was already dealing with my arthritis really conscientiously. And the course helped to reinforce that.

\section{I: How for example?}

P: That I was on the right track, in my opinion. That many of the things I did were right. But that I really needed to increase them a bit. (146)

The search for other reasons for program results revealed that the majority of the patients who increased in selfefficacy were not able to offer alternative explanations. Three participants reported serious conditions (cardiac disease and anemia) or a general decline of health. One patient stressed positive changes in his life (retirement and a new hobby). In the group that decreased in self-efficacy, clearly more alternative explanations in relation to health were summed up (long-term hospitalization, infarct, and general decline in health). Stressful events reported in this group included caring for a mother with dementia, a car accident, neighbor disputes, and stress at work after the participation in the program.

\section{Discussion}

The results revealed that only half of the group reported positive, internal motives for participation. A majority of these motivated participants increased in self-efficacy. Motivational problems were also detected in other studies [7].

All patients who said the program was offered to them at the right time increased in self-efficacy. The patients who judged participation as mistimed, however, were found in both groups with increased and decreased self-efficacy. We found that a clear majority were satisfied with their grouping in either the 'with' or 'without partners' group. Some dissatisfaction was only found in the 'without partner' group. However, it would be erroneous to conclude that results from the 'with partner' group were better. First, because the with-partner group showed unfavorable outcomes in the effect study [1]; second, because (dis-) satisfaction was not associated with effect on self-efficacy; and third, because patients who were satisfied with participating alone gave convincing reasons as to why this was best for them.

Some participants mentioned motivations related to participation in a research study in order to support scientific progress. These motivations have to be distinguished from motivations to participate in an educational program. When these programs are offered in clinical practice, the "research motivations" play no role.

This qualitative study revealed that subjective evaluations of effectiveness went well with quantitative changes in self-efficacy in nearly all cases.

In summary, the limited results seem mainly to be associated with low motivation for participation and for changing health behavior. Moreover, declines in health as well as stressful life events after participation in the program were probable alternative explanations for the limited effects of the PPP. None of the results point to partner participation as a cause of decreasing self-efficacy or increasing fatigue.

On a majority of issues, nearly all patients gave their evaluation; on others however, some participants did not comment. This limitation is hard to avoid in qualitative research that emphasizes patient perspective. Another limitation of this study may lie in the retrospectivity of the data. As the interviews were held 2 years after participation in the program, we could not control for recall bias, mental shifts, and adaptations. However, the answers were vivid and gave evidence of clear and detailed memory of the PPP. This limitation could have only been ruled out with the use of diaries during and after the program.

We suggest that both forms of the ASMP (with and without partner) should be offered to the patients. Patients themselves should make the choice what fits the best to them. To improve results, the following strategies should be 
considered: Firstly, the information about the program should be advanced to ensure that patients start with appropriate expectations. A few questions about motivation and outcome expectations could help patients decide whether they should sign up for the program [22]. Second, motivational interviewing techniques could be applied individually to enhance the intrinsic motivation to change health behavior [23]. Third, tailoring of interventions could match program content to participants' phase of coping [24]. An option would be to group patients according to their concerns and provide them with individual tailored information, tasks, and exercises via the computer and let them interact online with patients in similar conditions to ensure peer support.

Acknowledgment This study was supported by grants from the College voor Zorgverzekeringen and the Dutch Arthritis Foundation, The Netherlands. We wish to thank the patients who participated in this study.

Conflict of interest statement No conflict of interest.

Open Access This article is distributed under the terms of the Creative Commons Attribution Noncommercial License which permits any noncommercial use, distribution, and reproduction in any medium, provided the original author(s) and source are credited.

\section{References}

1. Riemsma RP, Taal E, Rasker JJ (2003) Group education for patients with rheumatoid arthritis and their partners. Arthritis Care Res 49:556-566

2. Lorig K, Ritter PL, Plant K (2005) A disease-specific self-help program compared with a generalized chronic disease self-help program for arthritis patients. Arthritis Care Res 53:950-957

3. Lorig K, Ritter PL, Laurent DD, Fries JF (2004) Long-term randomized controlled trials of tailored-print and small-group arthritis self-management interventions. Med Care 42:346-354

4. Barlow J, Turner A, Wright C (2000) A randomized controlled study of the arthritis self-management programme in the UK. Health Educ Res 15:665-680

5. Fries JF, Lorig K, Holman HR (2003) Patient self-management in arthritis? Yes!. J Rheumatol 30:1130-1132

6. Solomon DH, Warsi A, Brown-Stevenson T, Farrell M, Gauthier S, Mikels D, Lee TH (2002) Does self-management education benefit all populations with arthritis? A randomized controlled trial in a primary care physician network. J Rheumatol 29:362-368

7. Buszewicz M, Rait G, Griffin M, Nazareth I, Patel A, Atkinson A, Barlow J, Haines A (2006) Self-management of arthritis in primary care: randomized controlled trial. BMJ 333:879-882
8. Riemsma RP, Taal E, Kirwan JR, Rasker JJ (2002) Patient education programmes for adults with rheumatoid arthritis. BMJ 325:558-559 (Editorial)

9. Taal E, Riemsma RP, Brus HLM, Seydel ER, Rasker JJ, Wiegman O (1993) Group education for patients with rheumatoid arthritis. Patient Educ Couns 20:177-187

10. Martire LM, Schulz R, Keefe FJ, Starz TW, Osial Jr TA, Dew MA, Reynolds CF III (2003) Feasibility of a dyadic intervention for management of osteoarthritis: a pilot study with older patients and their spousal caregivers. Aging Ment Health 7:53-60

11. van Lankveld W, van Helmond T, Näring G, de Rooij DJ, van den Hoogen F (2004) Partner participation in cognitive-behavioral self-management group treatment for patients with rheumatoid arthritis. J Rheumatol 31:1738-1745

12. Keefe FJ, Blumenthal J, Baucom D, Affleck G, Waugh R, Caldwell DS, Beaupre P, Kashikar-Zuck S, Wright K, Egbert J, Lefebvre J (2004) Effects of spouse-assisted coping skills training and exercise training in patients with osteoarthritic knee pain: a randomized controlled study. Pain 110:539-549

13. Prochaska JO, Velicer WF, Rossi JS, Goldstein MG, Marcus BH, Rakowski W, Fiore C, Harlow LL, Redding CA, Rosenbloom D, Rossi SR (1994) Stages of change and decisional balance for 12 problem behaviors. Health Psychol 3:39-46

14. Bridle C, Riemsma RP, Pattenden J, Sowden AJ, Mather L, Watt IS, Walker A (2005) Systematic review of the effectiveness of health behavior interventions based on the transtheoretical model. Psychol Health 20:283-301

15. Taylor SE (2003) Health psychology. Mc Graw-Hill, New York

16. Gonzalez VM, Goeppinger J, Lorig K (1990) Four psychosocial theories and their applications to patient education and clinical practice. Arthritis Care Res 3:132-143

17. Taal E, Rasker JJ, Wiegman O (1996) Patient education and selfmanagement in the rheumatic diseases: a self-efficacy approach. Arthritis Care Res 9:229-238

18. Helgeson VS, Gottlieb BH (2000) Support groups. In: Cohen S, Underwood LG, Gottlieb BH (eds) Social support measurement and intervention. A guide for social scientists. University Press, Oxford, pp 221-245

19. Dracup K (1985) A controlled trial of couples group counseling in cardiac rehabilitation. J Cardiopulm Rehab 5:436-42

20. Lorig K, Chastain R, Ung E, Shoor S, Holman HR (1989) Development and evaluation of a scale to measure the perceived self-efficacy of people with arthritis. Arthritis Rheum 32:37-44

21. Pope C, Ziebland S, Mays N (2000) Qualitative research in health care. Analysing qualitative data. BMJ 320:114-116

22. Bode C, de Ridder DTD (2007) Investing in the futureidentifying participants in an educational program for middleaged and older adults. Health Educ Res 22:483-499

23. Miller WR, Rollnick S (2002) Motivational interviewing: preparing people for change, 2nd edn. Guilford Press, New York

24. Giraudet-Le Quintrec J-S, Mayoux-Benhamou A, Ravaud P, Champion K, Dernis E, Zerkak D, Ouslimani A, Courpied J-P, Revel M, Kahan A, Dougados M (2007) Effect of a collective educational program for patients with rheumatoid arthritis: a prospective 12-month randomized controlled trial. J Rheumatol 34:1684-1691 